\title{
A Team Formation Framework for Managing Diversity in Multidisciplinary Engineering Project
}

\author{
https://doi.org/10.3991/ijep.v7i1.6461 \\ Shawqi Mohammed Hussein \\ Universiti Teknologi Malaysia, Kuala Lumpur, Malaysia \\ shawqi80@gmail.com \\ Mahmudul Hasan \\ Universiti Teknologi Malaysia, Kuala Lumpur, Malaysia \\ mhasanucsi@gmail.com \\ Mohammed Golam Murtuza \\ Universiti Teknologi Malaysia, Kuala Lumpur, Malaysia \\ murtuza.taz@gmail.com
}

\begin{abstract}
Team formation is one of the essential elements in constructing effective teamwork of any team size that requires different skill sets. Diversity in team encourages students to challenge and compete with one another while searching for new ideas, which in turn can lead to a better team performance. In a well-functioning diverse teams, the students who performed poorly may gain benefit by observing how excellent students approach the assignments. They may also benefit by getting advice and assistance from the excellent students. Studies have shown that Malaysian university graduates lack of team skills. The purpose of this paper is to propose a framework for forming a diverse multidisciplinary team among engineering undergraduates based on selected criteria such as individual personality type, gender, and other relevant demographic information. The proposed framework can also be used to design an automated team-formation system based on the identified metrics. The purpose of the framework is to consolidate the existing team formation literature, and to develop and test interventions for maximizing individual member and team performance as a whole that makes an effective team. For this study, a multidisciplinary approach was used where first year engineering students from three different faculties, namely Faculty of Electrical Engineering (FKE), Faculty of Mechanical Engineering (FKM), and Faculty of Biosciences and Medical Engineering (FBME) at Universiti Teknologi Malaysia (UTM) worked on an innovation project using the Conceive, Design, Implement, and Operate (CDIO) framework. Keirsey Temperament Sorter was used as an instrument to identify an individual's personality type.
\end{abstract}

Keywords-Diversity, engineering education, multidisciplinary, computer supported team formation 


\section{Introduction}

Teamwork towards a common goal, achieve more than individual work by enabling greater transferability of skills. On the other hand, when members of a team do not collaborate together well, conflict, uncertainty, and an inability to achieve tasks goal can result, even when individual team members are highly qualified [1]. Multidisciplinary approach in teamwork often creates more innovation [2] and may achieve higher levels of performance on a team project [1]. Hence, to maximize effectiveness, teams should be balanced and comprised of diverse student characteristics rather than uniform [3].

Previous studies found that diversity in a team does not always increase a team's performance [2]. So to form a balanced and diverse team, members selection for a project should be done carefully [2], [4]. A number of team effectiveness models or frameworks have been developed and empirically tested by adopting input-processoutput (I-P-O) framework in earlier studies. But most of these model were based on industrial, service, and non-academic contexts rather than academic settings [5]. Very few studies examine team effectiveness based on the diverse multidisciplinary teams and there is a lack of research how to form a diverse multidisciplinary team [6]. Therefore, the present study aims to propose a framework for forming a diverse multidisciplinary teams among engineering undergraduates based on selected criteria such as individual personality type, gender, and other relevant demographic information. The purpose of the framework is to consolidate the existing team formation literature, and to develop and test interventions for maximizing individual member and team performance as a whole that makes an effective team.

\section{Reviews}

\subsection{Multidisciplinary Teamwork}

In recent years, there has been a major increase in the application of multidisciplinary work teams in engineering as a major approach towards work organization [7]. Engineering education has seen some major changes over the last few centuries. The pace of technological modernization has accelerated and require graduates to know more and to be able to adapt to emerging technologies. Many of these technologies extent traditional technical areas requiring professionals to work across disciplines. As the worldwide economy has urbanized, it has become a compulsory for engineers to be able to work across cultures and disciplines. To work in this kind of environment requires a strong and broad foundation as well as a diverse set of specialized skills that comprise the aptitude to work with multidisciplinary and multi-cultural teams [8].

Multidisciplinary teamwork demonstrates a team consisting of members with diverse expertise backgrounds and skills that can balance each other, and work together towards a similar track to attain the same goals [9]. Most of the employers of engineers considered teamwork as one of the most important abilities [10]. Team work is 
an essential element of engineering and is increasingly expected among students in higher education, employers, and accrediting bodies [11].

Multidisciplinary teams are very important in today's industry, so it is essential to generate and reflect this dynamic in the academic environment to better prepare the students for their job. This can be done by bringing students of various engineering and technical backgrounds together when working on a design project. Students can learn to work together in the academic environment where it reflects the current industry practices.

\subsection{Team Diversity}

According to American Society of Mechanical Engineers (ASME), it states that diversity are the ways in which we differ as persons or organizations, and the similarities that validate and inspire people and entities to work collaboratively jointly in order to achieve equally advantageous results [12]. The prime focus is generally placed on gender and society, along which also includes personality such as age, physical appearance, physical ability, thought styles, religion, nationality, socioeconomic status, belief systems, sexual orientation, education, world-view, problemsolving orientation, and learning style. Prior study argued that "growing understanding on how to measure diversity and its impact is necessary in order to understand the role diversity plays in advancing solutions, influencing society, and contributing to innovation, critical thinking, creativity, teamwork, entrepreneurship, leadership and global competencies" [12].

Diversity in a team can be outlined based on demographic and psychological factors. Demographic diversity refers to differences in observable attributes or demographic characteristics such as age, gender, and ethnicity. Psychological diversity refers to differences in underlying attributes such as skills, abilities, personality characteristics, attitudes, beliefs, and values. It can also include functional, occupational, and educational background [13]. Several studies acknowledged that teams should not be uniform and preferably be made up of members with different personality types [4].

Previous studies found that graduate engineering and business student teams diverse in openness exhibited more creativity on their innovation management class project [2]. The gender diversity of the team can affect how team members interact with one another, thereby affecting the performance of that team.

\subsection{Team Characteristics}

Team characteristics comprises of several interpersonal skills that makes a team more effective. For this study, team skills were grouped according to constructs such as participation, responsibility, preparation, flexibility, attendance, and communication.

Communication: Communication is one of the most essential teamwork process behaviors and has been widely researched in the team context [14]. In teams, communication is critical in providing, assessing, and synthesizing team members' inputs. If 
members do not communicate, the distinctive ideas of each member will not be shared. It was found that agreeableness affects performance through communication and cohesion. Communication precedes cohesion in time. Previous study found relationship between agreeableness and team performance and suggested that high levels of agreeableness can be achieved through face to face communication [15]. Communication are highly effective in enhancing teamwork [16]. However, it can be concluded that the team performance depends mainly on the type of communication.

Commitment: Team commitment is what motivates members to bind themselves to their team and devote effort on team's behalf [17]. It is crucial to organizational success and commitment to teams is an important predictor of team related behaviors [16]. As individuals feel confident of need for all team members, the benefits can be understand of working as a team. Over time, commitment reinforces effective teamwork [18]. The past results of path analyses demonstrate that the relationship between team based reward leadership and team performance is mediated by team commitment [17].

Responsibility: Team responsibility is conceptualized as being the autonomy of the team as a whole, whereas at other times the concept strictly refers to the responsibility of individual team members. Group responsibility is a primary determinant of escalation of commitment thus group responsibility for an initial funding decision should contribute to a group norm that favors ongoing commitment to a project. Most significant is the insight, resulting from the research that teams with high team responsibility and team member responsibility with regard to decisions concerning work preparation, work support along with work control have been found to contribute positively to team performance outcomes [19].

Flexibility: Flexibility is the ability to maintain an open attitude, accommodate different personal values and be receptive to the ideas of others [18]. Previous research shows that flexibility is critical to individual success in innovation [20]. It is seen from positive relationship between team flexibility and effectiveness. Moreover it will be stronger when the project is more complex [21]. It is also determined as a source of competitive advantage. Flexibility enhancement may be costly in the short run, but it gets easier over time [22].

The previous study provides evidence that individual benefits of both functional flexibility and team working may be enhanced while being practiced concurrently. Moreover, according to findings it indicates that functional flexibility may provide a double positive for manufacturers in the form of greater labor flexibility coupled with the benefit of contributing to effective team work [23].

Preparation: The first step towards being well prepared is to know about what teams are preparing. Team members should determine where the team is headed and examine what the conditions will be along the way. It was proposed that pre-team relational self-affirmation through one's personal network can be a significant element of preparation for contributing to a new team. So empirically validation of how pre-team relational self-affirmation can lead to sustained behavioral change. Based on previous results provide critical evidence that effect of a pre-team intervention can lead to both immediate and long-term outcomes in teams. However previous studies provide additional insights into how relational self-affirmation might relieve team 
members from being concerned about social acceptance, and thus improve team performance [24].

Participation: The sum of all positive behaviors is called effective participation. It reflects the professionalism and maturity of the members [25]. Moreover it constitutes taking part in team activities physically, emotionally and mentally along with the team process. Some of the reliable evidence to date on the direct impact of employee involvement through participatory arrangements such as teams on business performance [26]. It can be concluded that minority opinion member influence was positively related to team performance, indicating that greater minority influence relates to better team performance [27].

However it can be observed from previous research evidence that the more involved individual team members are in team regarding with what it does, how it does, and how decisions are made are more effective for the team. For this reason, many teams found themselves considering on how to increase levels of participation within the team [28].

\subsection{Team Effectiveness and Related Models/Frameworks}

Team effectiveness is a study of factors that influence a wide variety of team outcomes that meet or exceed the performance standard as well as maintain or enhance the capability of team members to work well in a team [29]. Team effectiveness is considered as a new attribute desired of graduates from engineering disciplines [30]. Effective teamwork is necessary to achieve effectiveness in student team performance outcomes [1].

A study conducted by [1] adapted an important model of team effectiveness known as an input-process-output (IPO) framework from the organizational behavior literature in academic setting. IPO framework helps to identify how student team collaboration mediates team characteristics (i.e., inputs) and the results of its work (i.e., performance effectiveness). Team size, gender diversity, and level of cohesion were considered as input factors. This study found that diversity of skill is more important rather than diversity of gender. This study also suggests that teamwork does not get affected by team size. However size of teams of this study was within an acceptable range to function normally.

Another study conducted by [5] developed a conceptual framework based on IPO framework to determine the relationship between input and output factors. This study suggests that different input factors such as work overload, team leadership, team climate influence different aspects of team effectiveness. Results shows that team climate is a key input factor that influences team effectiveness through team commitment as a process factor in an academic setting.

A team performance framework (or models) was developed by another study conducted by [31] to better understand the relationship between teamwork and performance. It shows that team outputs such as team effectiveness, errors etc. influenced by group "processes" related to team communication, coordination, leadership and finally decision making. On the other hand, group processes are influenced by a range of "inputs" such as tasks, group structures etc. 
In earlier studies, IPO framework did not include time as a factor and it could not distinguish multiple types of processes and outcomes. Due to the limitation and criticism of IPO another framework were developed by Ilgen at al. called input-mediatoroutcome (IMO) framework. IMO framework was the baseline for development of multi-method team performance measurement system in healthcare [32].

A study by [33] suggests that the key factors of effective teams can be divided into four general categories such as contextual factors (adequate resources, leadership and structure, climate of trust and a performance evaluation and reward system), composition factors (ability and personality of team members, allocating roles, diversity, size of the team and the members' preference and flexibility for teamwork), work design factors (autonomy and freedom, skill variety, task identity and task significance) and process factors (common purpose, specific goals, team efficacy, conflict levels, social loafing).

\subsection{Team formation, Personality and Team Performance}

Team formation is one of the essential elements in constructing effective teamwork. Team formation also known as team composition. Selecting the members of a team is the first task to form a successful team. Team formation also describes the structure of a team as well as roles. A better understanding of team formation could give significant insights and be used as a tool to form an effective team [34]. Team formation can vary in gender, race, education, and background of knowledge, in addition to measures of ability and personality.

Personality traits are commonly studied as important individual-level factors in teamwork and team performance. Knowledge of team member's personality types helps to understand team member behavior, managing the dynamics of the team and to know how team members interact well in a group setting to accomplish the task [35]. Previous studies found correlations between individual personality and performance on a team [2] [11]. Differences in personality type of the members on a team have the potential to improve team effectiveness by increasing diversity of perspectives and behaviors [11]. Extraversion and emotional stability positively influenced how a person felt about a work role [2].

\subsection{Keirsey Temperament Sorter}

In this study, Keirsey Temperament Sorter was used as a tool to identify an individual's personality when forming teams. It has been found that the groups having ESTJ character types are very opinionated and follow a conventional pathway unlike ISTJ group members, who are very calm and personal [36].

\section{$3 \quad$ Methodology}

The identification of diverse multidisciplinary team related studies involved a search of the ISI Web of Science, Science Direct, ACM digital library, ASCE, Taylor 
\& Francis, Emerald, Google Scholar databases for papers on team formation and its effectiveness in the academic and organizational setting. A review of literature regarding the diverse team formation and team effectiveness was conducted through a computerized search of the above mentioned accessible databases. Searches were carried out based on the key words of "diversity", "team formation", "team performance", "team effectiveness", "multidisciplinary", "team building”, "team personality", "team performance measurement" and "teamwork".

For this study, a multidisciplinary approach was used where first year engineering students from three different faculties, namely Faculty of Electrical Engineering (FKE), Faculty of Mechanical Engineering (FKM), and Faculty of Biosciences and Medical Engineering (FBME) at Universiti Teknologi Malaysia (UTM) worked on an innovation project using the Conceive, Design, Implement, and Operate (CDIO) framework. In Semester 1-2015/16, 103 students who enrolled in the Introduction to Engineering class were divided into 10 groups for developing a hospital food delivery robot consisting of three subsystems where FKE students are responsible for navigation system, FBME students worked on developing a robotic hand, and FKM students worked on the robot's mechanical machining. Student teams were formed based on the individual type of personality driven from their Keirsey Temperament Sorter report. Other factors considered for team formation included gender, race, and background knowledge on engineering. Team skills were grouped according to constructs such as participation, responsibility, preparation, flexibility, attendance, and communication.

\section{$4 \quad$ Results}

Drawing from research findings in organizational behavior, management, academic, medicine and psychology, this study extend the current understanding of team effectiveness and diverse multidisciplinary team formation. The previous models of team effectiveness adopted in this study were from several sources [1] [5] [31] [32] [33]. Figure 1 shows the conceptual framework of this research. It asserts Team formation as prerequisite for team which is an input factor. Team formation consists of diversity.

Diversity can be categorized into demographic and psychological diversity. Demographic diversity comprises of gender, race and background knowledge of engineering whereas psychological diversity comprises of individuals' personality. Keirsey Temperament Sorter is as an instrument to identify an individual's personality type. By using this framework, a diverse multidisciplinary team can be formed. All the parameters that has been identified as team formation metrics (e.g. gender, race etc.) can be used to develop an automated team-formation system. 


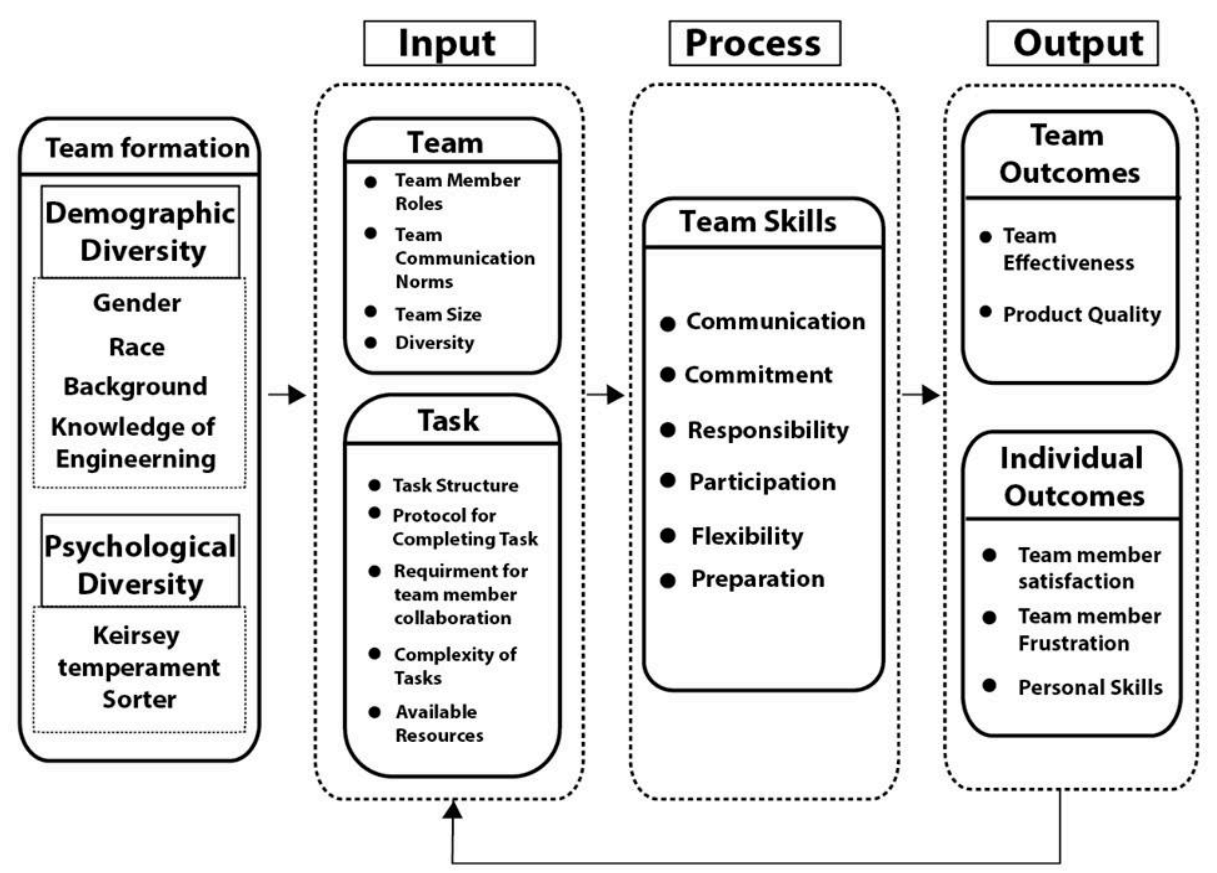

Fig. 1. Figure 1. Diverse multidisciplinary team formation framework

\section{Conclusion}

Diversity in team is important to provide opportunities for students with different personalities and skills to work together. Having diversity helps to ensure that a team has the skills, capability, and knowledge necessary for the successful completion of tasks. Therefore, this framework provides a better opportunity for students to build team skills and learn from one another, while focusing on achieving the tasks for the team projects. On the other hand this framework also save faculty time to form a diverse multidisciplinary team.

\section{Acknowledgment}

This study was encouraged by Universiti Teknologi Malaysia, and course instructors for Introduction to Engineering at the Faculty of Electrical Engineering (FKE), Faculty of Mechanical Engineering (FKM), and Faculty of Biosciences and Medical Engineering (FBME) at Universiti Teknologi Malaysia (UTM). 


\section{$7 \quad$ References}

[1] D. R. Deeter-Schmelz, K. N. Kennedy, and R. P. Ramsey, "Enriching Our Understanding of Student Team Effectiveness,” J. Mark. Educ., vol. 24, no. 2, pp. 114-124, 2002. https://doi.org/10.1177/0273475302242004

[2] J. Rhee, D. Parent, and A. Basu, "The influence of personality and ability on undergraduate teamwork and team performance," Springerplus, vol. 2, no. 16, pp. 1-14, 2013.

[3] L. K. Michaelsen and M. Sweet, "The essential elements of team-based learning," New Dir. Teach. Learn., vol. 2008, no. 116, pp. 7-27, Sep. 2008. https://doi.org/10.1002/t1.330

[4] M. Pollock, "Journal of Information Technology Management Investigating The Relationship Between Team Role Diversity And Team Performance In Information Systems Teams,” J. Inf. Technol. Manag., vol. XX, no. 1, pp. 42-55, 2009.

[5] Z. Omar and A. Ahmad, "Factors Contributing to Research Team Effectiveness: Testing a Model of Team Effectiveness in an Academic Setting," Int. J. High. Educ., vol. 3, no. 3, pp. 10-26, 2014. https://doi.org/10.5430/ijhe.v3n3p10

[6] R. J. Fornaro, M. R. Heil, and S. W. Peretti, "Enhancing technical communication skills of engineering students: an experiment in multidisciplinary design," 31st Annu. Front. Educ. Conf. Impact Eng. Sci. Educ. Conf. Proc. (Cat. No.01CH37193), pp. S2G-1-6, 2001. https://doi.org/10.1109/fie.2001.964037

[7] D. S. Strong and O. C. K1, "Towards Effective Multidisciplinary Engineering Education: The Multidisciplinary Design Stream at Queen 's University Professor and NSERC Chair in Design Engineering," 2002.

[8] E. A. Commission, "Criteria For Accrediting Engineering," 2016.

[9] H. Tang and E. Hsiao, "The advantages and disadvantages of multidisciplinary collaboration in design education," pp. 1-10.

[10] D. C. Davis and R. R. Ulseth, "Building Student Capacity for High Performance Teamwork," 120th ASEE Annu. Conf. Expo. Pap. 5944, p. 26, 2013.

[11] P. M. Ostafichuk and C. Naylor, "The Influence of Personality Type on Teamwork in Engineering Education,” Proc. 2013 CEEA Conf. (Montreal, June 17-20, 2013), pp. 1-7, 2013.

[12] D. A. Delaine, S. Paulo, and D. Williams, "Global Diversity in Engineering Education," no. September, 2015.

[13] D. van Knippenberg and M. C. M. C. Schippers, "Work Group Diversity," Annu. Rev. Psychol., vol. 58, no. 1, pp. 515-541, 2007. https://doi.org/10.1146/annurev.psych.58.1104 $\underline{05.085546}$

[14] B. H. Bradley, J. E. Baur, G. Christopher, and B. E. Postlethwaite, "Team Players and Collective Performance: How Agreeableness Affects Team Performance Over Time," 2013.

[15] A. Mart1, P. D. L. Carnicer, and M. Jose, "Teleworking and workplace flexibility: a study of impact on firm performance," vol. 36 Is 1, pp. 42 - 64, 2007.

[16] N. R. A. Symons, H. W. L. Wong, T. Manser, N. Sevdalis, C. A. Vincent, and K. Moorthy, "An observational study of teamwork skills in shift handover," Int. J. Surg., vol. 10, no. 7, pp. 355-359, 2012. https://doi.org/10.1016/j.ijsu.2012.05.010

[17] V. Rousseau and C. Aubé, "The reward - performance relationship in work teams: The role of leader behaviors and team commitment," 2016.

[18] S. Mickan and S. Rodger, "Characteristics of effective teams: a literature review." Aust. Health Rev., vol. 23, no. 3, pp. 201-208, 2000. https://doi.org/10.1071/AH000201

[19] H. Doorewaard and R. Huys, "Team responsibility structure and team performance Team responsibility structure and team performance," no. May, 2002. 
[20] S. J. Perry, E. M. Hunter, and S. C. Currall, "Managing the innovators: Organizational and professional commitment among scientists and engineers commitment among scientists and engineers," no. April, 2016.

[21] S. A. Mccomb, S. G. Green, and W. D. Compton, "Team flexibility's relationship to staffing and performance in complex projects : An empirical analysis," vol. 24, pp. 293-313, 2007.

[22] A. Mart1, P. D. L. Carnicer, and M. Jose, "Teleworking and workplace flexibility: a study of impact on firm performance," vol. 36 Is 1, pp. $42-64,2007$.

[23] K. F. H. Hvolby, "Effective teamworking: can functional flexibility act as an enhancing factor? An Australian case study," 2010.

[24] J. Lee and F. Gino, "Preparing the Self for Team Entry: How Relational Affirmation Improves Team Performance", SSRN Electronic Journal, 2016. https://doi.org/10.2139/ ssrn. 2753160

[25] C. Rohaida, B. Saarani, and N. Bakri, "Examining The Technical and Non Technical Member' s Participation in Cross-Functional Teams : A Case Study," Procedia - Soc. Behav. Sci., vol. 40, pp. 187-196, 2012. https://doi.org/10.1016/j.sbspro.2012.03.180

[26] D. C. Jones, "The Effects of Employee Involvement on Firm Performance: Evidence from an Econometric Case Study * By," no. August 2003, 2005.

[27] G. G. Park and R. D. Deshon, "A Multilevel Model of Minority Opinion Expression and Team Decision-making Effectiveness A Multilevel Model of Minority Opinion Expression and Team Decision-Making Effectiveness," vol. 95, pp. 824-833, 2010.

[28] A. Benson and M. Rice, Developing and sustaining effective teams. London: Royal College of Nursing, 2007.

[29] M. Borrego, J. Karlin, L. D. Mcnair, and K. Beddoes, "Team effectiveness theory from industrial and organizational psychology applied to engineering student project teams: A research review,” J. Eng. Educ., vol. 102, no. 4, pp. 472-512, 2013. https://doi.org/10.10 02/jee. 20023

[30] M. P. K. Sheridan, G. Evans, and D. Reeve, "A Proposed Framework for Teaching TeamEffectiveness in Team-Based Projects," Am. Soc. Eng. Educ., 2012.

[31] T. W. Reader, R. Flin, K. Mearns, and B. H. Cuthbertson, "Developing a team performance framework for the intensive care unit," Crit. Care Med., vol. 37, no. 5, pp. 17871793, 2009. https://doi.org/10.1097/CCM.0b013e31819f0451

[32] M. a Rosen, A. S. Dietz, T. Yang, C. E. Priebe, and P. J. Pronovost, "An integrative framework for sensor-based measurement of teamwork in healthcare.," J. Am. Med. Informatics Assoc., no. December 2013, pp. 1-6, 2014.

[33] S. Robbins, T. Campbell and T. Judge, Organizational behaviour. Harlow [u.a.]: Financial Times/Prentice Hall, 2010.

[34] M. Omar, Z. A. Aljasim, M. Ahmad, F. Baharom, A. Yasin, H. Mohd, and N. M. Darus, "Team Formation Model of Selecting Team Leader: an Analytic Hierarchy Process (Ahp) Approach,” ARPN J. Eng. Appl. Sci., vol. 10, no. 3, pp. 1060-1067, 2015.

[35] S. Clinebell and M. Stecher, "Teaching teams to be teams: An exercise using the Myers Briggs type indicator and the Five- Factor personality traits," J. Manag. Educ., vol. 27, no. 3, p. 23, 2003. https://doi.org/10.1177/1052562903027003006

[36] R. H. Rutherfoord, "Using personality inventories to help form teams for software engineering class projects," ACM SIGCSE Bull., vol. 33, no. 3, pp. 73-76, 2001. https://doi.org/10.1145/507758.377486 


\section{Authors}

Shawqi Mohammed Hussein is with the Advanced Informatics School, Universiti Teknologi Malaysia, Kuala Lumpur, Malaysia (e-mail: shawqi80@gmail.com).

Mahmudul Hasan and Mohammed Golam Murtuza, was with the Advanced Informatics School, Universiti Teknologi Malaysia, Kuala Lumpur, Malaysia (e-mail: mhasanucsi@gmail.com; murtuza.taz@gmail.com).

Article submitted 28 November 2016. Published as resubmitted by the authors 23 January 2017. 